\title{
Macrophagic Activation Syndrome (MAS) Revealing Systemic Lupus Erythematosus
}

\author{
Sana Aourarh $^{1}$, Fatima Zahra Lazrak ${ }^{1}$, Saida Eddyb ${ }^{1}$, Adil Jahdaoui ${ }^{1}$, Sanae Sayagh ${ }^{1}$, \\ Mustapha Ait Ameur², Mohamed Chakour ${ }^{2}$ \\ ${ }^{1}$ Department of Laboratory of Hematology of Faculty of Medicine, University Cadi Ayyad, University Hospital Mohammed VI, Marrakech, \\ Morocco \\ ${ }^{2}$ Department of Laboratory of Hematology of Faculty of Medicine, University Cadi Ayyad, Military Hospital Avicenna, Marrakech, \\ Morocco
}

Email address:

dr.sanita@hotmail.fr (S. Aourarh)

\section{To cite this article:}

Sana Aourarh, Fatima Zahra Lazrak, Saida Eddyb, Adil Jahdaoui, Sanae Sayagh, Mustapha Ait Ameur, Mohamed Chakour. Macrophagic Activation Syndrome (MAS) Revealing Systemic Lupus Erythematosus. American Journal of Laboratory Medicine.

Vol. 5, No. 1, 2020, pp. 28-31. doi: 10.11648/j.ajlm.20200501.14

Received: December 26, 2019; Accepted: January 15, 2020; Published: February 10, 2020

\begin{abstract}
Introduction: Macrophagic activation syndrome (SAM) or hemophagocytic lymphohistiocytosis is an anatomoclinical entity resulting from an inappropriate proliferation and activation of macrophagic cells. This rare but serious syndrome can be primary or secondary to certain pathologies dominated by infections and neoplasias. More rarely, it is secondary to connectivitis, in particular to systemic lupus erythematosus (LES). The aim of this work is to report the case of SAM revealing a systemic lupus erythematosus and to discuss the triggering factors. Observation: A 27-year-old patient who presents to the emergency room for arthralgia evolving for a week in a context of fever and deterioration of the general state hospitalized in the nephrology department for bicytopenia and functional renal failure. The hemogram showed anemia at 10.7 $\mathrm{g} / \mathrm{dL}$, normocytic, normochromic, aregenerative (reticulocytes at $18 \mathrm{G} / \mathrm{L}$ ), hyperleukocytosis at $10.5 \mathrm{G} / \mathrm{L}$ and platelets at the lower limit of normal at $158 \mathrm{G} / \mathrm{L}(338 \mathrm{G} / \mathrm{L}$ in September 2006). In view of argenerative anemia, a myelogram was performed showing the presence of hemophagocytosis figures. The remainder of the biological examination revealed hyperferritinaemia at $1017 \mathrm{ng} / \mathrm{mL}$ with an increase in LDH $930 \mathrm{U} /$ Let a CRP at $18.15 \mathrm{mg} / \mathrm{L}$. The patient was transferred to the internal medicine department for etiological assessment, clinical and paraclinical examinations showed arthritis with deep ADP and pleural mass, leuconeutropenia with native DNA and positive antinuclear antibodies (ANA) as well as the coombs test which was positive, The diagnosis of SLE was retained in her on the criteria of the ACR.
\end{abstract}

Keywords: Hemophagocytic Lymphohistiocytosis, Systemic Lupus Erythematosus, Autoimmunity

\section{Introduction}

Macrophagic activation syndrome, or hemophagocytic lymphohistiocytosis, is a rare disorder of the reticuloendothelial system leading to an inadequate and exaggerated immune response against the host. It is characterized by non-specific activation of the monocyte-macrophage system, the translation of which is a proliferation and tissue infiltration of activated histiocyte-macrophages, with phagocytosis of the blood elements inducing peripheral cytopenia [1-3].

The symptomatology is not very specific, dominated by fever, deterioration of the general state and splenomegaly.
The suggestive biological signs are cytopenia, liver abnormalities, increased $\mathrm{LDH}$, ferritin and triglycerides. Its diagnosis is often late and the prognosis is grim.

A distinction is made between primary macrophagic activation syndromes, associated with genetic abnormalities, some of which are known, and secondary macrophagic activation syndromes, which can be induced by several pathologies which have in common a significant stimulation of the immune system, notably viral infections, bacterial and parasitic, neoplasms with malignant hemopathies at the forefront, but more rarely systemic diseases such as systemic lupus erythematosus.

Systemic lupus erythematosus is a non-specific autoimmune organ disease of multifactorial etiology, 
progressing by successive attacks interspersed with remissions. Biologically, the disease is characterized by the production of multiple autoantibodies against the constituents of the nucleus, including the native anti-DNA specific for the disease. Macrophagic activation syndrome is a rare and littleknown complication of systemic lupus erythematosus, which can be life-threatening.

Objective: We report the observation of a patient hospitalized in the internal medicine department of the CHU Med VI of Marrakech for a macrophagic activation syndrome complicating a systemic lupus erythematosus.

\section{Observation}

This is a 27 year old patient, who presented to the emergency room for arthralgia evolving for a week in a context of fever and deterioration in general condition, hospitalized in the nephrology department for insufficiency functional renal (Urea at $0.42 \mathrm{~g} / \mathrm{l}$ and creatinine at $20 \mathrm{~g} / \mathrm{l}$ ) associated with bicytopenia.

On clinical examination, the patient presented a fever at $37.8^{\circ} \mathrm{C}$ after taking paracetamol, and for eight days feverish peaks above $39^{\circ} \mathrm{C}$, without chills or night sweats. The deterioration of the general state became debilitating, with intense asthenia and anorexia for a few days.

The hemogram showed anemia at $10.7 \mathrm{~g} / \mathrm{dL}$, normocytic, normochromic, aregenerative with a reticulocyte rate at 18 $\mathrm{G} / \mathrm{L}$, a hyperleukocytosis at $10.5 \mathrm{G} / \mathrm{L}(\mathrm{N}: 4-10)$ and a rate platelets at the lower limit of normal, at $158 \mathrm{G} / \mathrm{L}(338 \mathrm{G} / \mathrm{L}$ in September 2006).

The initial biological examinations made it possible to objectify a hypertriglyceridemia at $2.4 \mathrm{~g} / \mathrm{dl}(\mathrm{N}: 1.5-2 \mathrm{~g} / \mathrm{dl})$, without hypercholesterolemia, hyponatremia at $132 \mathrm{mmol} / \mathrm{L}$ (N: 135-150mmol/L), LDH at $930 \mathrm{U} / \mathrm{L}(\mathrm{N}: 135-225 \mathrm{U} / \mathrm{I}), \mathrm{CRP}$ at $18.15 \mathrm{mg} / \mathrm{L}(\mathrm{N}:<5 \mathrm{mg} / \mathrm{l})$, hyperferritinemia at $1017 \mathrm{ng} / \mathrm{ml}(\mathrm{N}$ : $30-400 \mathrm{ng} / \mathrm{ml}$ ), pancreatic and renal examinations were normal.

The presence of angerogenic anemia associated with different clinical and biological disturbances motivated the realization of an emergency myelogram. The latter objectified a rich marrow with a slight granulocytic hyperplasia and especially the presence of many macrophages with typical figures of hematophagocytosis (figures 1,2 ).

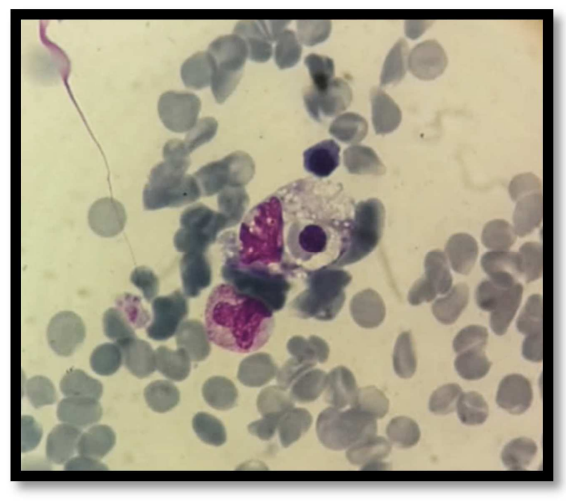

Figure 1. Macrophage phagocytizing an erythroblast. We observe the presence of the hemophagocytosis halo.

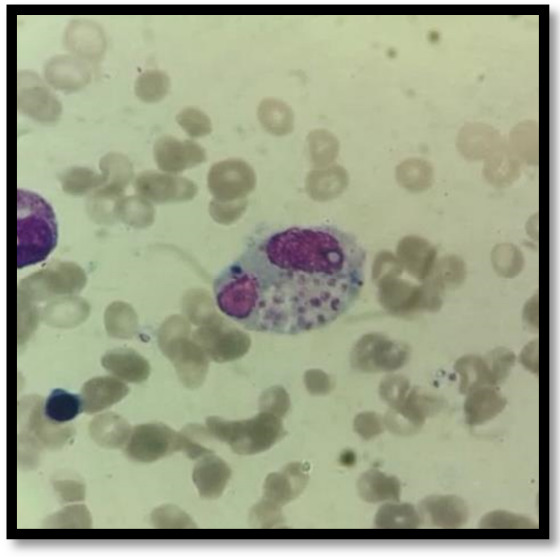

Figure 2. Macrophages phagocytosing platelets.

The patient was transferred to the internal medicine department for an etiological assessment and appropriate care. The dermatological examination showed a discreet erythema of the cheekbones and upper eyelids, the rest of the integument was strictly normal, arthritis with deep lymphadenopathy and a pleural mass. We had carried out examinations in search of an infectious etiology, none of which was contributing. Hepatitis B, hepatitis C, HIV 1 and 2, CMV serologies were negative.

In search of a deep infectious focus, we had performed an abdominopelvic ultrasound, a chest X-ray, a sinus X-ray and a transthoracic heart ultrasound, the results were normal.

At the autoimmune level, we found anti-nuclear antibodies (speckled appearance at 640), anti-Ssa antibodies and positive anti-DNA antibodies.

The diagnosis of MAS associated with systemic lupus erythematosus was retained. The evolution was favorable after the first bolus of corticosteroid therapy.

\section{Discussion}

MAS is a state of hyper-inflammation in which several pathophysiological mechanisms are entangled. The onset of this pathology seems to be linked to an abnormal activation and a defect in cytotoxicity of the T lymphocytes (allowing the causative agent to persist), essentially of Th1 and Natural Killer (NK) profile, without limitation of their power of activation nor of cytokine production [5]. This significant production of pro-inflammatory cytokines will stimulate the macrophagic response [7]. On the other hand, activated macrophages will produce other cytokines which will exert a positive feedback on the lymphocytes thus maintaining an amplification loop. Macrophage activation is responsible for both clinical and biological signs of MAS. Fever, which is an almost constant sign of MAS, is secondary to the increased production of gamma interferon, IL-6 or IL1. Pancytopenia arises from phagocytosis, cytokine apoptosis and myelosuppression. Organomegaly is linked to tissue infiltration by activated macrophages and lymphocytes. Hyperplasia of intrahepatic macrophages (Kupffer cells) is thought to be the cause of hepatic cytolysis. 
Hypertriglyceridemia is thought to be secondary to the inhibition of lipoprotein lipase by inflammatory cytokines (TNF- and IL-1) [11]. Hyperferritinemia is the consequence of erythrophagocytosis, liver damage and systemic inflammation [1].

MAS has been described in several system or inflammatory diseases. Still disease and systemic lupus erythematosus are the most common $[3,4]$. It is a rare but serious complication, the immunosuppression induced by the disease itself and exacerbated by immunosuppressive treatments which can promote the appearance of MAS.

MAS is based on the presence of clinical, biological, and cytological or histological criteria. The French group of LHH (JANKA 2012; GFLHH 2007) has defined diagnostic criteria, it consists of having at least five criteria out of the eight to carry the diagnosis of MAS (Table 1). Our patient met six out of eight criteria $[1,6]$.

The clinical signs of LES and MAS can be confused, only the biological data pointed us towards a syndrome of macrophagic activation in particular the presence of an arégenerative anemia. The myelogram is essential to establish the diagnosis of MAS by highlighting hemophagocytosis figures. Other cytological examinations (lymph node aspiration, liver biopsy, examination of ascites fluid, cerebrospinal fluid, skin, lung biopsy, etc.) can be informative but are not performed routinely [7].

We find a rich marrow with infiltration by histiocytes and macrophages of benign cytological aspect, the number of which is discreetly increased. Macrophages are morphologically benign (nucleus not very large, with fine chromatin, sometimes nucleated, with a low nucleocytoplasmic ratio) and contain numerous intracytoplasmic vacuoles containing figured elements of the blood (erythrocytes, erythroblasts, granulocytes, platelets, lymphocytes) or their hematopoietic precursors intact or partially digested. The same cell can phagocyte several cell types at the same time.

However, it should be remembered that hemophagocytosis is a physiological phenomenon and for some authors, the percentage of macrophages in hemophagocytosis is an important diagnostic criterion ( $>2 \%$ for Wong et al [8], and $>$ $3 \%$ for Tsuda and al [15]). No study has found a relationship between the number of spinal histiocytes and the severity of the disease [10]. Imakushu [1] and Henter [11] require an figure of hemophagocytosis without any notion of percentage.

Other biological abnormalities are often associated; argenerative anemia with stigmas of hemolysis [12], hemostasis abnormalities due to hypofibrinogenemia or thrombocytopenia progressing to disseminated intravascular coagulation $[6,13]$, increased $\mathrm{LDH}$, hepatic cytolysis and hyponatremia. The level of procalcitonin can guide the etiological diagnosis.

Deep pancytopenia, hyperferritinemia and hypertriglyceridemia are unusual in lupus and should suggest MAS (hyperferritinemia in $95.4 \%$ of cases [14], increase in LDH in $92.3 \%$ of cases, hypertriglyceridemia in $89.6 \%$ of cases [15] and abnormal liver function tests in $80.8 \%$ of cases) [16]

In our case the assay of AAN and native anti-DNA antibodies were positive, this agrees with the results of literature whose assay of antinuclear antibodies (AAN) and native anti-DNA antibodies (DNA) were positive in $100 \%$ and 84 respectively., 7\% of cases and hypocomplementemia existed in $77 \%$. At least one of these immunological abnormalities was present whenever the LES was incriminated in the responsibility of MAS.

The appearance of MAS during SLE seems to define a severe form of SLE, with a risk of recurrence, and frequent lupus flares which are difficult to control with prolonged immunosuppressive therapy. The literature review showed a mortality rate of $9.6 \%$ during MAS associated with SLE, which is lower than the average observed for all causes of MAS combined (49\%).

\section{Conclusion}

Macrophagic activation syndrome can be a rare mode of onset of systemic lupus erythematosus and an unexplained etiology of fever during the course of this systemic disease.

The clinical signs of MAS and LES can be confused, and only biological examinations such as ferritinemia, the determination of triglycerides and liver enzymes can guide the diagnosis.

The discovery of hemophagocytosis figures on the myelogram allows us to conclude.

Table 1. Diagnostic criteria for macrophagic activation syndrome according to the French group of LHH and presented by the patient.

\begin{tabular}{ll}
\hline Diagnostic criteria & \\
\hline At least five of the eight criteria & Patient \\
\hline Fever & Yes \\
splenomegaly & Yes \\
Cytopenia affecting at least two lines & \\
Hemoglobin $<9 \mathrm{~g} / \mathrm{dL}$ & Yes \\
Platelets $<100,000 / \mathrm{mm}^{3}$ & \\
Polynuclear neutrophils $<1000 / \mathrm{mm}^{3}$ & Yes \\
Ferritin $>500 \mu \mathrm{g} / \mathrm{L}$ & Yes \\
hypertriglyceridemia $>3 \mathrm{mmol} / \mathrm{L}$ and $/$ or hypofibrinogenemia $(<1.5 \mathrm{~g} / \mathrm{L})$ & Not realized \\
Soluble $I L 2$ receptor $(\mathrm{sCD} 25)>2400 \mathrm{U} / \mathrm{mL}$ & Not realized \\
NK activity decreased or absent & Yes \\
\hline Hemophagocytosis (marrow, spleen, lymph nodes) & \\
\hline
\end{tabular}




\section{References}

[1] Imashuku S. Differeiîtial diagnosis of heinophagocytic syndrome: underlying disorders and selection of the most effective treatment. Int J Hematol. 1997; 66: 135-5 1.

[2] Kumakura S., Ishikura H., Kondo M., Murakawa Y., Masiida J., Kobayashi S. Autoimmune-associated lieinopliagocytic syndrome. Mod Rheumatol. 2004; 14: 205-15.

[3] Dhote R., Simon J., Papo T., Detournay B., Sailler L., Andre M. H., et al. Reactive hemophagocytic syndrome in adult systeinic disease: report of twenty-six cases aiid literature review. Arthritis Rheuin. 2003; 49: 633-9.

[4] Papo T., Andre M. H., Amoura Z., Lortholary O., Triboiit B., Guillevin L., et al. The spectrum of reactive heinophagocytic syndroine in systeinic lupus erythematosus. J Rheumatol. 1999; 26: 927-30.

[5] Berrady R, Bono W, Le syndrome d'activation lymphohistiocytaire (SALH), Annales Françaises d'Anesthésie et de Réanimation 33 (2014) 26-32.

[6] Wong KF, Chan JK. Reactive hemophagocytic syndrome - a clinicopathologic study of 40 patients in an Oriental population. Am J Med 1992; 93: 177-80.

[7] Karras A., Hermine O. Syndrome d'activation inacrophagiq ie. Rev Med Interne. 2002; 23: 768-78.

[8] Wong K. F., Chan J. K. Reactive hemophagocytic syiîdroine-a cliiîicopatliologic study of 40 patients in Oriental population. Ain J Med. 1992; 93: 177-80.

[9] Tsuda H. Hemophagocytic syndroine (HPS) in children and adults. Int J Heinatol. 1997; 65: 215-26.

[10] Tiab M., Mechinaud F., Hamidou M., Gaillard F., Raffi F., Harousseau J. L. Syndromes hémophagocytaires: une série de 23 observations. Ann Med Interiie (Paris). 1996; 147: 138-44.

[11] Henter J. 1., Elinder G., Soder O., Ost A. Incidence in Sweden and clinical features of familial heinophagocytic lymphohistiocytosis. Acta Paediatr Scand. 1991; 80: 428-35.

[12] Michot M, Hiéc M, Galicier L, Lambotte O, Michel M, BlochQueyratf C, Herminef $\mathrm{O}$, Le syndrome d'activation lymphohistiocytaire de l'adulte, La Revue de médecine interne 34 (2013).

[13] Kaito K, Kobayashi M, Katayama T, Otsubo H, Ogasawara Y, Sekita T, et al. Prognostic factors of hemophagocytic syndrome in adults: analysis of 34 cases. Eur J Haematol 1997; 59: $247-53$.

[14] Eminenegger U., Reiiners A., Frey U., Fux C., Bihl F., Seinela D., et al. Reactive macrophage activation syndrome: a simple screening strategy and its potential in early treatment initiation. Swiss Med Wkly. 2002; 132: 230-6.

[15] Tsuda H., Shirono K. Ser iinlipids in adult patients with hemophagocytic syndroine. Am J Hematol. 1996; 53: 285.

[16] de Kergiienec C., Hillaire S., Molinie V., Gardin C., Degott C., Erlinger S., et al. Hepatic manifestations of heinophagocytic syndrome: a stiidy of 30 cases. Ain J Gastroenterol. 2001; 96: 852-7.

[17] Janka GE, Hemophagocytic syndromes, Blood Rev 2007; 21: $245-53$. 